clinician. I am sorry I got it wrong when I said it was an original idea.

The Royal Free Hospital

Department of Child and Adolescent Psychiatry

Pond Street

London NW3 2QG

\section{Portrayal of women in advertisements}

SIR: The paper by Ashton (Journal, May 1991, 158 (suppl. 10), 30-35) on psychotropic drug prescribing for women, quotes an American study (Prather \& Fidell, 1975) which showed that advertisements for psychoactive drugs show significantly more women. The same conclusion was reached by Penfold \& Walker (1984) who also looked at North American journals.

In a retrospective study of our own, we have examined all advertisements for psychotropic drugs appearing in the British Journal of Psychiatry over the last 30 years and surprisingly find the situation to be different. We looked at the three categories of antidepressants, anxiolytics, and antipsychotics, and found the portrayal of gender within each group of advertisements to be in line with accepted prevalences of illness (e.g. Kendell \& Zealley, 1988), i.e. there was no gender bias in numbers of women shown.

What we did find, however, was a marked difference in the portrayal of women. Whereas depressed or anxious men tended to be shown at work, or worrying about deadlines, women were more often portrayed in the home or with children. In 30 years, only one woman has been shown in a professional role - as a teacher in 1961! Similarly there has never been a female doctor portrayed - despite the fact that about one-third of members of the Royal College of Psychiatrists are women.

Kendell, R. E. \& Zealley, A. K. (1988) Companion to Psychiatric Studies. Edinburgh: Churchill Livingstone.

Penfold, S. \& Walker, G. A. (1984) Women and the Psychiatric Paradox. Milton Keynes: Open University Press.

Prather, J. E. \& Fidell, L. S. (1975) Sex differences in the content and style of medical advertisements. Social Science and Medicine, 9, 23-26.

Matthew Jelley JOHN OWEN

Fromeside Clinic

Blackberry Hill

Stapleton

Bristol BS16 1ED

\section{Independent evaluation of new drugs}

SIR: Healy (Journal, June 1991, 158, 737-742) is right to draw our attention to the weaknesses of the
Hamilton Rating Scale in the assessment of response to antidepressant medication, and to question the marketing policies of drug companies to which clinicians are exposed without the benefit of 'independent trials'. While dilating upon the link between dopamine and serotonin he does not consider the relationship between noradrenaline and serotonin. The implication is that theories of depression involving these two neurotransmitters are mutually exclusive. Close anatomical relationships with reciprocal connections have been demonstrated between the brainstem raphe nuclei and the locus coeruleus suggesting closely related systems (Descarries \& Leger, 1978; Fuxe et al, 1978).

Sulser (1987) has described the complex relationship between the changes in noradrenergic receptors in response to antidepressant medication and the role of serotonin in these changes. In drug-free animals, lesions of the serotonin system produce an increase in the density of $\beta$-adrenoceptors. In the absence of serotonin, downregulation of the $\beta$-adrenoceptor in response to antidepressants does not occur. This downregulation is a common feature of many treatments for depression (Leonard, 1988). Acute reductions in serotonin may reverse antidepressantinduced downregulation. The mechanism of interaction between the two may be modulated by 'second' or 'third' messenger activated protein kinases (Sulser, 1987).

Leonard (1988) suggests that the adaptive changes in the serotonin and noradrenergic receptors in response to chronic antidepressant administration have a similar time course to the improvement seen clinically in the depressed patient.

Clearly the story is a complex one and much remains to be clarified. The marketing strategies of the drug companies exploit these areas of doubt. While agreeing with Healy that there is a need for 'independent' studies and critical evaluation of these, this cannot be achieved by ignoring the wealth of evidence that serotonin in conjunction with noradrenaline has an important role in the molecular biology of depression.

Descarries, L. \& Leger, L. (1978) Serotonin nerve terminals in the adult rat. In Interactions Between Putative Neurotransmitters in the Brain (eds S. Garattini, J. F. Pujol \& R. Samanin), pp. 355-367. New York: Raven Press.

Fuxe, K., Hokfelt, T. \& Agnali, L. F. (1978) Mapping out central catecholamine neurones. In Psychopharmacology: A Generation of Progress (eds M. A. Liplan, A. DiMascio \& K. F. Killam), pp. 67-94. New York: Raven Press.

LeONARD, B. A. (1988) Pharmacological effects of serotonin reuptake inhibitors. Journal of Clinical Psychiatry, 49 (suppl. 8), 12-17.

SULSER, F. (1987) Serotonin-norepinephrine receptor interactions in the brain: implications for pharmacology and pathophysiology 